\title{
Quem conta um conto, aumenta um ponto: escrita e transmissão do caso na clínica com crianças
}

Who tells a tale, adds a tail: the case writing in clinic with children

Quien cuenta un sucedido sin aumentar, no sabe contar: escritura y transmisión del caso en la clínica con niños

\author{
Andrea Gabriela Ferrari* \\ André Antônio Beltrami ${ }^{* *}$ \\ Marilia Zancan Frantz $z^{* *}$
}

\begin{abstract}
Resumo
Neste artigo, propomos um instrumento para escrita de caso clínico de crianças, pensado com base nas discussões no Núcleo de Ensino, Pesquisa e Extensão em Clínica Interdisciplinar da Infância da Clínica de Atendimento Psicológico da UFRGS. Percorremos trabalhos atinentes à importância do registro para a prática psicanalítica e formação de novos terapeutas. Salientamos a particular relevância da escrita de caso para a clínica-escola, na qual a temática da formação é fundamental. Dos debates no Núcleo e apoiados na teoria da constituição do sujeito, derivamos três eixos capazes de nortear a escrita dos casos e de respeitar singularidades: a criança no discurso parental, aquilo que ela capturou para si do que lhe foi oferecido, a sua inserção no laço social. A utilização da ficha de registro, superadas as resistências iniciais, demonstrou tratar-se de potente e adequado instrumento para os fins propostos.
\end{abstract}

Palavras-chave: Transmissão. Relato de caso. Psicanálise com crianças. Clínicas escola.

\footnotetext{
Abstract

From discussions at the Teaching, Research and Extension Center on Childhood Interdisciplinary Clinic at the Psychological Clinic Care of UFRGS, we present here a proposition of children clinical case report. To make it possible, we studied some works about the importance of

Texto recebido em abril 2014 e aprovado para publicação em novembro de 2014.

Professora no Departamento de Psicanálise e Psicopatologia da Universidade Federal do Rio Grande do Sul; coordenadora do Núcleo de Ensino, Pesquisa e Extensão em Clínica Interdisciplinar da Infância da Clínica de Atendimento Psicológico da UFRGS; membro do NEPEIA (Núcleo de Ensino Pesquisa e Extensão em Infância e Adolescência - CNPq). Endereço: Rua Ramiro Barcelos, 2600 - Santa Cecília, Porto Alegre-RS. CEP: 90035-003. E-mail: andrea.ferrari@ufrgs.br.

** Especialista em Atendimento Clínico pela Clínica de Atendimento Psicológico da Universidade Federal do Rio Grande do Sul. Endereço: Rua Ramiro Barcelos, 2600 - Santa Cecília, Porto Alegre-RS. CEP: 90035-003. E-mail: aabltrm@yahoo.com.br.

*** Psicóloga, especialista em Atendimento Clínico pela Clínica de Atendimento Psicológico da Universidade Federal do Rio Grande do Sul. Endereço: Rua Ramiro Barcelos, 2600 - Santa Cecília, Porto Alegre-RS. CEP: 90035-003. E-mail: mz.frantz@ gmail.com.
} 
case reporting to psychoanalytic clinic and we point the importance of case reporting when it comes to a school clinic, where education is a fundamental concern. In the scope of these discussions and backed by the subject constitution theory we provide three guidelines to the writing of children's cases without obliterate the aspects that give them singularity. The first guideline regards the parental speech, the second points to what the child captured of what was offered, the third refers to the inclusion in the social bond. Overcame initial resistance, the use of this elaborated record, demonstrated to be a powerful and appropriate instrument for the intended purposes.

Keywords: Transmission. Case reporting. Children psychoanalysis. School clinic.

\section{Resumen}

En este trabajo proponemos un instrumento para la escritura de caso clínico de niños pensado a partir de discusiones en el Núcleo de Enseñanza, Investigación y Extensión en Clínica Interdisciplinar de la Infancia de la Clínica de Tratamiento Psicológico de la Universidad Federal de Rio Grande do Sul. Nos apoyamos en trabajos sobre la importancia del registro para la práctica psicoanalítica y para la formación de nuevos terapeutas. Destacamos la particular relevancia de la escritura de caso para la clínica-escuela, donde la temática de la formación es fundamental. De los debates en el Núcleo y apoyados en la teoría de la constitución del sujeto, derivamos tres ejes capaces de orientar la escritura de los casos y de respetar singularidades: el niño en el discurso parental, aquello que él capturó para sí mismo de lo que le fue ofrecido, su inserción en el lazo social. La utilización de la ficha de registro, después de superar resistencias iniciales, se mostró un potente y adecuado instrumento para las finalidades propuestas.

Palabras clave: Transmisión. Relato de casos. Psicoanálisis de niños. Clínica escuela.

\section{Do caso à escrita: algumas questôes sobre a transmissão}

U ma questão importante para aqueles que trabalham na área psi é a escrita do caso clínico. Quando escrevemos, quando registramos os apontamentos da sessão, quando narramos o caso na supervisão, quando reunimos nossos escritos para compor um relato de caso clínico, estamos reproduzindo objetivamente as palavras do paciente, seu discurso, ou se trata daquilo de que recordamos, marcado pela singularidade da escuta? Há um dito popular que bem traduz o tema: "Quem conta um conto aumenta um ponto". 
Escrever sobre um caso clínico, registrar os apontamentos de uma sessão é uma atividade que nos remete ao contexto da problemática da narrativa da realidade fática e da ficção a partir do fato; da conjugação daquilo que se produziu a partir da relação transferencial entre terapeuta e paciente.

Freud (1905a/1996), ${ }^{1}$ ao questionar sua teoria da sedução, após um percurso de construção teórico-clínica e concluir que nem todas as histéricas estavam sendo ou haviam sido abusadas de fato, mostrou-nos que nos interessa, na clínica psicanalítica, o acontecimento tal como foi tomado pelo sujeito e o seu desdobramento, aquilo que o paciente tomou para si, como ele representou o fato. O que nos importa, portanto, é a realidade psíquica e a construção possível a partir do laço transferencial.

Um dos casos inaugurais relatados por Freud (1905b/1996), e que pode nos ajudar a pensar a questão da escrita e transmissão de caso clínico, é o Caso Dora, publicado sob o título Fragmentos da análise de um caso de histeria. Dora foi uma jovem de 16 anos que consultou com Freud por mais ou menos três meses ao final de 1900. Seu tratamento foi interrompido por ela mesma em dezembro daquele ano. Foi um tratamento curto e cujos esclarecimentos foram organizados em torno de dois sonhos. Os enunciados destes foram registrados por Freud logo após as sessões e o caso escrito de memória logo após o término do tratamento, em janeiro de 1901. Apesar disso, Freud foi postergando sua publicação até 1905 .

Nas notas preliminares, Freud fala do problema que era para ele a publicação de seus casos clínicos, tanto por questões técnicas quanto por preocupações referentes à quebra de sigilo. Se antes da publicação do Caso Dora era acusado por seus colegas de não fornecer detalhes importantes, acreditava que agora seria acusado de expor os segredos mais íntimos da paciente. Justifica a publicação por entendê-la como um meio de transmissão da prática que fundava, considerando que, além dos deveres com a paciente, também tinha um dever com a ciência. Além do mais, tomou cuidado para não dar detalhes que pudessem revelar a identidade de Dora e, caso ela mesma lesse o relato de seu tratamento, não descobriria nada que já não lhe tivesse sido comunicado. Em todo caso, Freud concordava que as preocupações com o sigilo acabavam por restringir o uso de material clínico que poderia ser útil em seu relato. Outra dificuldade apontada por ele na elaboração dos relatos dos casos foi referente à não tomada de notas em sessão, e a como registrar para publicação a história de um tratamento mais prolongado.

1 A primeira data indica o ano de publicação original da obra, e a segunda indica a edição consultada pelo autor. Ambas serão pontuadas somente na primeira citação da obra no texto. Nas seguintes, será registrada apenas a original. 
Nas recomendações aos médicos que exercem a psicanálise, Freud (1912/1996) alertava a respeito da tomada de notas durante as sessões de análise, dizendo que, além de não terem grande valor e serem fatigantes, tais relatos não davam conta do que se passava durante a sessão. O Pai da Psicanálise recomendava que se exercitasse a atenção flutuante e que as notas que se julgassem necessárias tomar fossem feitas em um momento posterior. Ao mesmo tempo, sabemos da importância que os relatos de fragmentos de casos tiveram na obra de Freud para a construção e para a transmissão da psicanálise.

De acordo com Porge (2009), os relatos de experiência clínica em Freud tinham a intenção de fazer reconhecer a dignidade científica da psicanálise, mas não somente isso. Estava comprometido com a invenção de uma prática e, assim, da mesma maneira que relatava os casos para demonstrar o que havia sido por ele teorizado, interpretava a fala de seus pacientes e tentava convencê-los de suas teorias, por acreditar que o reconhecimento de uma teoria do inconsciente fazia parte do processo terapêutico. $\mathrm{O}$ que estava em questão nos seus relatos, enfim, era a transmissão da psicanálise, seja para os seus pares ou para os seus pacientes. $\mathrm{Na}$ obra freudiana, finalidade terapêutica e finalidade didática e científica não se diferenciam.

Três questões apontadas por Freud (1905b) são relevantes para nós neste momento: a organização do caso em torno de dois sonhos (norteadores da escrita do caso), o fato de Freud tê-lo redigido de memória após seu término (o que resta da relação transferencial) e o fato de o tratamento ter sido interrompido pela vontade da paciente. Podemos considerar esse caso a inauguração de um estilo que permite a transmissão da teoria e prática psicanalítica, permitindo preservar a especificidade de uma história particular. Freud (1909a, 1909b, 1911/1996, 1918/1996), nos outros casos que escreveu, transmite e sustenta, com base em norteadores, seus questionamentos e modificações teórico-clínicos.

Podemos pensar a respeito do que se pinça na especificidade de um caso, um traço fundamental, ou, como Czermak (2007) aponta, um fato clínico. Fundamental no sentido daquilo que funda essa subjetividade e daquilo que fundamenta a interpretação. Bernardino (2010) refere que o traço aponta para uma originalidade (como origem e novidade), serialidade (fazer parte de uma série de humanos que faz marcas no sujeito) e corte (a separação do grupo que o constituiu). Questôes importantes a serem consideradas em um escrito clínico.

Sobre o relato baseado na memória do analista, temos o caso como uma ficção que se constrói em uma relação transferencial. Russo (2011) lembra que, no material clínico, não pode ser colocado o tudo o que ocorre em sessão, visto que o acesso do psicanalista ao seu objeto ocorre por meio de inferências que estão 
pautadas, entre outras coisas, pelo seu marco conceitual. Freud (1937/1996) coloca que as construçôes oferecidas ao paciente no intuito de levantar a barreira do recalque são conjecturas que serão confirmadas ou não no percurso do tratamento, preferencialmente com o surgimento da lembrança recalcada. Nesse aspecto, é importante marcar a diferença entre construção e interpretação abordada por Figueiredo (2004). Na construção se pretende um arranjo dos elementos discursivos com o objetivo de compartilhar e transmitir elementos do caso, o que não ocorre com a interpretação. Esta, mais pontual, visaria a dar um sentido àquilo que foi dito. Assim,

A "construção do caso clínico" em psicanálise é o (re)arranjo dos elementos do discurso do sujeito que "caem", se depositam com base na nossa inclinação para colhê-los, não ao pé do leito, mas ao pé da letra. Incluímos aí também as açōes do sujeito, entendendo que são norteadas por uma determinada posição no discurso [...]. Nunca é demasiado lembrar que o caso não é o sujeito (Figueiredo, 2004, p. 79).

Então, é baseado naquilo que a formação teórico-clínica aponta que a experiência transferencial do encontro analista-analisando poderá ser organizada e narrada. Nesse contexto, cabe levantar a questão a respeito da formação do psicanalista, uma vez que esta deve ser entendida no sentido de formação do inconsciente, conforme aponta Porge (2009), e da qual teorias estabelecidas a priori num modelo de formação profissional não dão conta. Segundo o autor, os escritos freudianos não apenas relatavam casos, mas, por seu estilo romanceado, colocava também a si mesmo no texto, referindo que a divisão entre a história que se conta (extratos do caso clínico) e a teoria que a interpreta (consideraçóes teóricas) coloca Freud ora como narrador/autor ora como terceiro que intervém sobre a história, ficando claro também que é impossível traçar uma fronteira entre os elementos factuais da história (o sujeito, a doença, o tratamento) e a teoria que os engloba. Ainda, se pensamos na experiência analítica como um trabalho sobre ou a partir do inconsciente, temos de levar em conta a relação transferencial que se estabelece entre paciente e analista, e que impossibilita que este último não esteja implicado como sujeito no seu relato. "O romance permite uma pluralidade de níveis enunciativos e, nesse sentido, permanece fiel ao processo de análise" (Porge, 2009, p. 22). Assim, a verdade do sintoma não está contida na exatidão dos fatos objetivos, pois como lembra Porge, 
A análise é uma experiência de fala, descontínua, com efeitos ligados ao tempo, à antecipação, ao "só-depois" [après-cup], com afastamento entre o enunciado e a enunciação, com intervenções do analista... Uma estenografia linear, cronológica, não daria conta dos efeitos de verdade que se produzem no sujeito. Tal é a dificuldade do analista: se quer permanecer na verdade de sua experiência, não pode fiar-se na exatidão de uma tomada de notas (Porge, 2009, p. 19).

O autor refere que, além de as publicações de relatos de caso constituírem para Freud a afirmação de seu desejo, elas são importantes do ponto de vista da terapêutica, pois, pelo processo de transmitir a verdade de um sujeito com base em suas formaçôes do inconsciente, permitem o acesso a um saber inédito. É por isso que os relatos de experiências clínicas são a via freudiana privilegiada para tratar do tema da transmissão da clínica psicanalítica.

Do mesmo modo que existem os desvios na análise para que a verdade abra para si um caminho, é preciso um desvio para que essa mesma verdade possa ser retransmitida a um público amplo ou restrito. Esse desvio se chama: forma de relatar [mise en récit]. Freud faz uma triagem do material, reordena sua disposição e cronologia, quer dizer, procede às deformaçóes que restituem a temporalidade do desvelamento da verdade (Porge, 2009, p. 20).

\section{A Clínica de Atendimento Psicológico da UFRGS e as entrevistas iniciais}

A Clínica de Atendimento Psicológico (CAP) da UFRGS (Universidade Federal do Rio Grande do Sul) é uma clínica-escola vinculada ao curso de Psicologia dessa universidade e se propóe a oferecer atendimento psicológico às pessoas da comunidade, bem como a formação dos alunos do curso de graduação e pós-graduação (Brizio \& Petry, 1994). As entrevistas iniciais são um modelo de recebimento das pessoas que procuram a CAP pela primeira vez. Foi idealizado pela Prof. ${ }^{a}$ Martha Brizio, com base nos questionamentos sobre as listas de espera que se formavam e pelas recorrentes faltas dos pacientes às primeiras entrevistas agendadas. Uma vez por semana, as pessoas que desejarem atendimento são escutadas, por ordem de chegada, pela equipe da clínica. Esse é um dispositivo que prioriza a escuta do paciente, desde a sua chegada, até a possibilidade de formulação de uma demanda. Nas entrevistas iniciais, o tempo de escuta pode variar, conforme o estabelecimento da demanda de tratamento: algumas semanas, alguns meses ou, até mesmo, alguns dias ou uma única entrevista. Se o que está em jogo é a construção da demanda, não há como se prever um tempo 
cronológico para a atividade. Segundo Brizio (1994), nas entrevistas iniciais, é oferecida ao paciente uma escuta que permite demarcar o que é próprio do sujeito no pedido de atendimento. Nas entrevistas iniciais com crianças, além da escuta da criança e de seus pais, fazem-se interconsultas com aqueles que a encaminharam para atendimento, por exemplo, a escola ou o pediatra.

No ano de 2011, por algumas contingências institucionais, foi criado o que denominamos Núcleo de Ensino, Pesquisa e Extensão em Clínica Interdisciplinar da Infância. $\mathrm{O}$ objetivo subjacente à construção do núcleo foi o de fomentar e intensificar os atendimentos às crianças. Além disso, pelas mudanças contemporâneas a respeito da infância, percebemos a necessidade de um lugar formalizado de trocas e discussões para dar bordas e contornos aos casos que nos chegam. Começamos, então, a nos reunir semanalmente para tratar de casos que precisavam de um amparo institucional. Em nenhum momento, as discussóes do núcleo suplantaram as supervisóes, mas se complementaram principalmente naqueles casos em que a abordagem interdisciplinar tinha de se fazer presente.

Muitas vezes, nós nos deparávamos com um paciente que já tinha estado em atendimento na clínica, mas, por diversos motivos, tinha interrompido ou finalizado seu atendimento. Ao resgatar o relato do caso feito pelo terapeuta ${ }^{2}$ em formação que o havia atendido anteriormente, encontrávamos escritos tão extensos que era impossível resgatar um traço particular do caso, ou tão sucintos que também nos impediam de fazer qualquer leitura sobre sua especificidade. A interdisciplinaridade do grupo também se fez presente no sentido de que tínhamos que nos escutar e nos questionar nas diferentes disciplinas que compõe a CAP e o Núcleo (Psicanálise, Psicologia Sistêmica, Fonoaudiologia Clínica, Psicopedagogia Clínica, Serviço Social, Terapia Ocupacional), no intuito de pensar o encaminhamento e a direção do tratamento, de modo a garantir sua continuidade. Daí a nossa preocupação com a escrita e transmissão do caso dentro da instituição.

\section{A escrita do caso de crianças, a transmissão e a formação na Clínica de Atendimento Psicológico da UFRGS}

Nestas páginas, estamos abordando o tema da escrita de caso dentro do contexto de uma clínica-escola, levando em consideração suas características específicas e seu funcionamento particular. Além da especificidade das entrevistas iniciais, soma-se que, em instituições como a nossa, os atendimentos não necessariamente finalizam ao término do estágio ou do curso de especialização do terapeuta, mas se considera, na singularidade de cada situação, se o paciente

2 Utilizamos o termo terapeuta para nos referir aos estagiários de Ênfase em Processos Clínicos: Psicanálise e Psicopatologia do Instituto de Psicologia da UFRGS e para os alunos da Especialização em Atendimento Clínico da CAP-UFRGS. 
continuará ou não sendo atendido por outro terapeuta em formação vinculado à clínica. Algumas vezes, essa cadeia de encaminhamentos contempla mais de dois terapeutas e, então, a compilação de relatos, com base nas diversas anotações, com a intenção de compreender o percurso do caso, torna-se tarefa no mais das vezes bastante complexa.

Acrescente-se a essa particularidade institucional a própria dificuldade com o ato de escrever, a escrita em si, com o escrever tudo ou então escrever nada. São aquelas situações quando, não raro, deparamo-nos com relatos pródigos, cronológicos, tipos de relatos que tudo reproduzem e nada produzem ou então a situação reversa: a avareza angustiante do registro escrito. Figueiredo (2004) aponta para uma distinção interessante entre o relato clínico e o caso clínico. O relato clínico seria aquele que apresenta uma riqueza de detalhes da história, das cenas, etc. Já o caso clínico seria o produto extraído pelo analista, no qual organiza, com base nos significantes advindos do sujeito, uma composição traçada pelo discurso. A construção baseada na história se torna possível pelo atravessamento do campo conceitual que a psicanálise nos oferece. $\mathrm{Na}$ escrita do caso, os significantes se fazem presentes no sentido de conduzir uma linha, quiçá ficcional, que nos leve à especificidade daquele encontro.

Assim, é de importância fundamental, por causa da nossa característica de clínica-escola, a necessidade de nortear o registro do que se passou durante os atendimentos, pois quando o paciente continua na instituição, acompanhado por outro terapeuta, o efeito de transmissão do relato do caso clínico vai ser elementar para dar sustentação ao reinício do tratamento. Além disso, sendo a CAP também um lugar de formação de novos terapeutas, é importante acentuar que a transmissão de que se trata não é apenas do caso, mas também da prática clínica.

A importância do relato ainda se faz presente porque pensamos que, na nossa instituição, observa-se a constituição de pelo menos dois níveis de laços transferenciais: primeiro, o paciente se dirige à CAP e é aí que o significante UFRGS faz sua marca, constitui-se um laço; segundo, o laço transferencial que se estabelecerá com a pessoa responsável pelo atendimento. Todavia, como é possível que durante o tratamento venha a se constituir uma cadeia de diferentes terapeutas, o laço com a instituição faz a amarração que permite a continuidade do trabalho, apesar da ruptura no momento em que acontece a passagem do paciente ao novo atendimento. E poderíamos conjeturar até mesmo um terceiro tipo de amarração que tem a ver com a relação entre os terapeutas do caso e os supervisores. Diferente do consultório particular, quando o paciente é quem abandona, rompe o laço e procura outro psicólogo, aqui, a transferência com a instituição e os diversos enlaces estabelecidos precisam de algo que lhes dê uma 
vinculação. Assim, toma relevante importância o relato do caso, fazendo enlaces, amarrações e transmissão.

Todavia, note-se que a proposta não é a de organizar um relato comum, burocrático, sequência de narrativas de sessóes ordenadas cronologicamente. A proposta é a de compor um escrito organizado segundo norteadores que possibilitem uma narrativa coerente, clara e concisa a qual permita, no âmbito da clínica-escola, tanto a compreensão quanto a transmissão do caso clínico. E, importante, a interlocução através de um código compartilhado com as diversas especialidades clínicas oferecidas pela instituição.

\section{Tempos constitutivos como norteadores da escrita do caso de crianças}

A peculiaridade da escrita de casos que propomos não diz respeito, necessariamente, a uma publicação, mas sim a um registro que vise à sua transmissão dentro da instituição, de modo a que o trabalho tenha continuidade e que ao mesmo tempo sirva como um instrumento para o terapeuta que o escreve. A escrita, como refere Guimarães (2008), é um fazer cotidiano que orienta a direção da cura pela possibilidade de formalizar o material bruto trazido pelos pacientes. Para isso é necessário buscar norteadores que permitam a transformação do fático em si em fato clínico. Para Bernardino (2010), a escolha dos norteadores da escrita do caso sustenta a prática a partir de uma construção teórica, permitindo não somente a transmissão da psicanálise como também o isolamento de um traço da especificidade do caso que se repete no percurso do trabalho.

Considerando que os norteadores nos permitem a seleção de dados relevantes para a discussão do caso no âmbito da nossa prática nos atendimentos das crianças, pareceu-nos ser fundamental pensar a respeito da viabilidade de encontrar alguns nos quais os relatos dos atendimentos pudessem se pautar, encontrar uma direção e, ao mesmo tempo, respeitar a especificidade do traço do caso.

Em busca desses norteadores que nos permitissem a formalização e a transmissão de casos de crianças atendidos na CAP, deparamo-nos com o trabalho organizado por Kupfer e Voltolini (2008) sobre O uso de indicadores em pesquisas de orientação psicanalítica: um debate conceitual. A questão que nos interessou se refere à universalidade das operações psíquicas fundamentais para a constituição de um sujeito. Jerusalinsky (2008) aponta para quatro eixos teóricos para organizar e orientar a seleção dos indicadores na primeira infância: suposição de um sujeito, alternância presença/ausência, estabelecimento da demanda e função paterna. Esses eixos se referem às operações formadoras do fantasma fundamental, que organizará a vida psíquica do sujeito em constituição. 
Para saber sobre a posição subjetiva da criança, temos de recorrer às manifestaçôes típicas da infância, a saber: o brincar, a imagem inconsciente do corpo, o estatuto da fantasia, as formações da lei, a posição do sujeito na linguagem. Além disso, como lembra Bernardino (2010), na clínica com crianças, pelo fato de se tratarem de sujeitos em constituição, o fato clínico é atravessado pela fala da criança, por meio suas manifestações, mas também dos pais, professores, das instituições que dela cuidam. Assim, podemos identificar o traço no caso clínico de crianças pelo texto da fala, do brincar e desenhar, do que é dito pelos adultos que a cercam e também pela relação transferencial estabelecida entre o analista e os diferentes personagens que fazem parte do cotidiano da criança.

Essas reflexões nos possibilitaram a discussão da necessidade de construirmos norteadores para a escrita do caso de crianças atendidas na CAP que apontassem para sua transmissão sem perder de vista o ocorrido no encontro do terapeuta com a criança e seu entorno. Baseando-se no roteiro da AP $3,{ }^{3}$ formulamos no Núcleo Interdisciplinar da Infância algumas questóes que consideramos importantes de serem observadas (e, na medida do possível, respondidas) pelos terapeutas que atendem crianças, de modo a dar mais consistência e rigor aos escritos. Nosso objetivo era o de dar orientação aos terapeutas a respeito do que é importante ser registrado, de modo que o relato do caso servisse a todas as práticas da CAP (Psicanálise, Fonoaudiologia, Psicopedagogia e Terapia Sistêmica de Casal e Família), funcionando tanto como suporte para a transmissão do caso dentro da instituição quanto como suporte na formação dos terapeutas.

Avistamos, assim, a necessidade de que algumas questôes fossem colocadas de modo a nortear o trabalho de registro a partir dos atendimentos, o que serviria também como ponto de apoio para situar elementos importantes de serem escutados pelos estudantes na ocasião do trabalho clínico. Chegamos à conclusão de que era preciso dar mais elementos para que a construção de alguns norteadores da escrita do caso se desse de maneira diferente. Organizamos uma ficha baseada em três temáticas: a primeira considerando o discurso parental; a segunda considerando o que a criança capturou para si daquilo que lhe foi oferecido; e a terceira levando em conta a inserção da criança no laço social.

A primeira questão considerada é que um sujeito se constitui como tal a partir dos efeitos enunciativos e libidinizantes do Outro no corpo do bebê. Os

3 O trabalho apresentado por Lerner (2008) refere-se à Pesquisa Multicêntrica de Indicadores Clínicos de Risco Infantil (IRDI), subsidiada pela FAPESP, CNPq e Ministério da Saúde, a qual é produto de articulações entre Psicanálise, Pediatria, Nutrição, Fonoaudiologia e Psiquiatria, em torno da noção de risco para o desenvolvimento. Segundo os autores da pesquisa, não se trata de traduzir para a Psicanálise as diversas especialidades nem de almejar uma versão superior ou mais bem-acabada dos fenômenos, mas sim de buscar expansão de pontos que encontram limitaçôes em seu campo de origem. Assim, profissionais da saúde e educação aplicaram em crianças de 0 a 18 meses de todo o País um protocolo que contém 31 indicadores de risco para o desenvolvimento infantil. A AP3 (avaliação psicanalítica de crianças de 3 anos), apresentada por Alfredo Jerusalinsky (2008) e outros, é um instrumento confeccionado para avaliar, aos 3 anos de idade, as crianças que foram previamente submetidas aos IRDI, buscando validar os indicadores. 
enunciados e investimentos libidinais lançados para o bebê estão amparados pelo desejo dos pais diante desse corpo que, em princípio, sustenta a ilusão de que o filho poderá driblar as impossibilidades com as quais os pais tiveram de se haver ao longo de sua história: sua majestade, o bebê. Esse princípio nos levou a considerar como um dos norteadores a história do casal e processo de individuação em relação à família de origem e conjugalidade e a pré-história e história primordial da criança. Ou seja, pensar a respeito da história constitutiva de cada um dos pais e o que dessa história se atualiza quando do nascimento do filho (Ferrari, Piccinini \& Lopes, 2006). Além disso, é importante ter em mente que, em geral, um filho é concebido quando algo falta ao casal. O bebê, muitas vezes, é fruto da tentativa de restituição da completude gerada pelo enamorar de duas pessoas. Nesse aspecto, as identificações recíprocas que o tomam como mais filiado a um dos pais, e que ele explicita como traço identificatório do incômodo em relação ao outro, dizem do tensionamento narcísico de um dos pais em relação à criança.

O nascimento do filho permite aos pais uma série de operações que os ressituam ante sua própria castração. Nesse aspecto, a forma de falar sobre o filho nos permite supor se estão fazendo deste uma extensão do próprio corpo ou se toleram que se possam colocar certas resistências àquilo que eles lhe demandam. Considerar o lugar da criança no discurso dos pais e a suposição de sujeito dos pais em relação à criança possibilita esboçar hipóteses diagnósticas importantes a respeito da estruturação subjetiva dessa criança. É diferente que os pais se coloquem alguma interrogação a respeito do porquê o filho está apresentando determinado sintoma ou que não o façam (Flesler, 2011).

Esses dois aspectos relacionam-se também com a capacidade operativa que os pais têm na transmissão das regras e valores culturais e dos interditos em geral. Somente se pode transmitir um não desde que a castração tenha se inscrito nos pais, desde que a metáfora paterna tenha operado o suficiente para não sustentar a gratificação narcísica totalizante na relação com o filho (Lévy, 2008). Este aspecto é norteado pela temática transmissão da lei, das regras e dos valores; das hierarquias e das fronteiras.

Pensamos que esses aspectos organizam a escrita no que se refere ao lugar que os pais ocupam na clínica com crianças e nos permitem pensar na necessidade ou não de um trabalho mais próximo desses pais. Não podemos deixar de considerar esse aspecto visto o sofrimento atual apontado pelas crianças de certa fragilização das fronteiras, o que gera uma necessidade de recompor certas bordas que permitam referenciar essa criança ante o Outro. Não é à toa o aumento de queixas relativas à falta de limites e agressividade vistas em crianças e mesmo um aumento significativo de queixas relativas à hiperatividade. 
Podemos considerar que os norteadores descritos dão conta daquilo que da história infantil parental se atualiza no encontro com o filho. Passamos agora a descrever a segunda parte, como a criança se posiciona em seus tempos constitutivos.

É fundamental o movimento de antecipação dos pais diante daquilo que a criança consegue de fato realizar, pelo oferecimento de enunciados identificantes (Aulagnier, 1991) que permitem que o bebê se situe como sujeito. Mas a criança não captura absolutamente tudo o que lhe é destinado. Aqui é onde podemos observar o que Bernardino (2004) denominou certa liberdade subjetiva por parte da criança. Nesse aspecto, é a posição da criança na linguagem, ou seja, como a criança se posiciona na construção da sua narrativa: se se coloca como sujeito, a pobreza ou riqueza simbólica sinalizada através do que ela enuncia como the sendo ou não próprio, se fala de si em primeira ou terceira pessoa, entre outras manifestações, permite-nos situar em que tempo constitutivo ela se encontra e como está operando a separação da constituição de seu desejo frente àquilo que os pais lhe destinaram.

Outra manifestação que se refere aos tempos constitutivos da criança é o brincar, a fantasia, a expressão gráfica e plástica, manifestações típicas da infância e que nos permitem trabalhar com seu sofrimento. Mais uma vez, essas manifestações nos dizem do tempo constitutivo e são consideradas por alguns autores (Jerusalinsky, 2008; Flecher, 1989) como sinais de estruturação psíquica, ou seja, como a criança vai bordeando a falta conforme vai se colocando para ela o efeito divisório da linguagem (Lacan, 1988). Essas manifestaçôes da infância também nos sinalizam a relação da criança com o corpo; reconhecimento da imagem no espelho; diferenciação sexual e autonomia diante de suas necessidades corporais.

A terceira parte da ficha se refere à inserção da criança no social. Isso é muito importante de ser marcado, já que é frequente que seja em razão de uma fratura dessa inserção que a criança é encaminhada para atendimento. Muitas vezes é devido a alguma problemática na escola ou mesmo de relacionamento com outra criança da família ou da comunidade à qual pertence que os pais se questionam a respeito de um possível sofrimento de seu filho. Assim a natureza dos vínculos da criança (fraternos, sociais, escola) nos pareceu ser uma temática imprescindível para nortear a escrita dos casos de crianças que nos chegam. Isso também nos sinaliza as potencialidades da criança quando encontramos dificuldades dos pais em se encarregarem de suas funçôes. Poder considerar os vínculos da criança para além da família nuclear permite pensar também em intervenções possíveis quando os pais, por diferentes questôes, não conseguem sustentar sua parentalidade. A função da escola para a criança (aprendizagem, função simbólica e subjetividade) 
é outro norteador que nos diz de um tempo constitutivo da criança, no qual os semelhantes e as aprendizagens formais tomam uma importância suprema na saída da conflitiva edípica. Com a queda das figuras parentais, as relações de amizade passam a ocupar um lugar preponderante no acesso do sujeito às configuraçôes sociais. Pensar se a criança consegue se vincular com outros fora do âmbito familiar dá conta da apropriação da metáfora paterna e da simbolização da lei. Há algo em comum que permite compartilhar códigos de convívio na infância prescindindo da presença concreta dos adultos.

Temos utilizado essa ficha para nortear nossas discussões clínicas, e isso tem nos ajudado não somente na questão da transmissão da psicanálise para os novos terapeutas, mas também na permissão de que a história daquele atendimento ocorrido na CAP não se perca quando da interrupção do tratamento pela saída daquele que o estava escutando.

\section{Questôes para não concluir...}

A questão da escrita do caso tem se colocado para nós como algo desafiador. Surge a partir da pergunta de como elaborar um escrito que priorize, ao mesmo tempo, a transmissão do caso, a transmissão da psicanálise com crianças e a formação de novos terapeutas. Somos uma clínica de atendimento psicológico que pertence a uma universidade, que tem como um de seus objetivos a articulação entre a pesquisa, o ensino e a extensão. Tentando respeitar essa articulação e pela constatação de que o material relatado não dava conta da especificidade do caso (pela sua extensão nos detalhes acontecidos nas consultas ou pela avareza de palavras), começamos a questionar a necessidade de se criar um norte para a escrita produzida nos atendimentos realizados na instituição.

Como transmitir aos terapeutas em formação a noção de construção de caso? A construção do caso é a possibilidade de rearranjar os elementos discursivos, com base em determinado marco conceitual, que se depositam no terapeuta pelo encontro transferencial. Mas como viabilizar essa noção para aqueles que estão começando a sua prática clínica? Foi considerando o marco conceitual da constituição do sujeito e suas operações universais que pudemos organizar os elementos trazidos pelo caso na relação transferencial com o terapeuta que o atende, com o Núcleo que sustenta as discussões e com a supervisão que ampara a escuta.

Inicialmente encontramos resistências por parte dos terapeutas em formação em utilizar a ficha. Referiam que era muito complexa, que daria muito trabalho ou mesmo que não poderiam capturar do caso todos os pontos que ela abordava. Como coordenadores do trabalho, insistimos na sua utilização pela potência 
que vislumbrávamos para a formação dos novos terapeutas e para a transmissão da psicanálise com crianças. Foi proposto pelos coordenadores que quem fosse discutir o caso no Núcleo deveria escrevê-lo com base nesses norteadores, considerando o material trabalhado na supervisão.

Vencidas as resistências, já nas primeiras discussões de caso escrito com base na ficha com os norteadores, o depoimento dos participantes das discussóes de caso do Núcleo, bem como as diferenças perceptíveis na qualidade dos registros, tem confirmado seu potencial não só para a formação de terapeutas e a transmissão da psicanálise, mas também como instrumento que ajuda a construir a direção para o tratamento.

Pensamos que a escrita do caso, amparada em três temáticas (discurso parental, posicionamento subjetivo da criança e sua inserção no laço social) permite capturar seu traço conforme fundamenta a escrita, respeitando as características de originalidade, serialidade e corte apontadas por Bernardino (2010).

Pretendemos, com esse trabalho, questionar as possibilidades de transmissão da clínica psicanalítica nas clínicas-escola, de apontar para a importância do que se escreve sobre o caso para a formação e para a pesquisa, mas também com o que se escreve para arquivar daquela pessoa que recorreu a determinada instituição demandando atendimento.

Quem conta um conto aumenta um ponto...

\section{Referências}

Aulagnier, P. (1991). Nascimiento de un cuerpo, origen de una história. In L. Hornstein (Org.). Cuerpo, história e interpretación. (pp. 117-170). Paidós: Buenos Aires.

Bernardino, L. (2004). Aspsicoses não decididas da infância: um estudo psicanalítico. São Paulo: Caso do Psicólogo.

Bernardino, L. (2010, janeiro-junho). O traço do caso na clínica psicanalítica com crianças e adolescentes. Revista da Associação Psicanalitica de Porto Alegre, $38,20-28$.

Brizio, M. (1994, dezembro). Apresentação. Questão - Revista da Clínica de Atendimento Psicológico da UFRGS, 1. 
Brizio, M. \& Petry, P. (1994, dezembro). As entrevistas iniciais na Clínica de Atendimento Psicológico da UFRGS: limites e possibilidades. Questão-Revista da Clínica de Atendimento Pscicológico da UFRGS, 1, 19-21.

Czermak, M. (2007). Qu'est-ce qu'um fait clinique? Qu'appelle-t-on un fait Clinique. Journal française de psychiatrie, 30, 4-6.

Ferrari, A.; Piccinini, C. \& Lopes R. S. (2006, setembro-dezembro). O narcisismo no contexto da maternidade: algumas evidências empíricas. Psico, 37 (3), 271278.

Figueiredo, A. (2004). A construção do caso clínico: uma contribuição da psicanálise à psicopatologia e à saúde mental. Revista Latinoamericana de Psicopatologia Fundamental, 7 (1), 75-86.

Flecher, M. (1989). Algumas observações sobre os sintomas das crianças. In A. Souza (Org.), Psicanálise de crianças (pp. 38-46). Porto Alegre: Artes Médicas.

Flesler, A. (2011). El niño en análisis y las intervenciones del analista. Buenos Aires: Paidós.

Freud, S. (1905a). Três ensaios sobre a teoria da sexualidade. In J. Salomão (Trad.). Obras completas (1996, Vol. 7, pp. 119-231). Rio de Janeiro: Imago. (Publicado originalmente em 1905a).

Freud, S. (1905b). Fragmento da análise de um caso de histeria.In J. Salomão (Trad.). Obras completas (1996, Vol. 7, pp. 15-116). Rio de Janeiro: Imago. (Publicado originalmente em 1905b).

Freud, S. (1909a). Análise de uma fobia em um menino de cinco anos. In J. Salomão (Trad.). Obras completas (1996, Vol. 10, pp. 13-133). Rio de Janeiro: Imago. (Publicado originalmente em 1909a).

Freud, S. (1909b). Notas sobre um caso de neurose obsessiva. In J. Salomão (Trad.). Obras completas (1996, Vol. 10, pp. 137-276). Rio de Janeiro: Imago. (Publicado originalmente em 1909b).

Freud, S. (1911). Notas psicanalíticas sobre um relato autobiográfico de um caso de paranoia (dementia paranoides). In J. Salomão (Trad.). Obras completas (1996, Vol. 12, pp. 15-89). Rio de Janeiro: Imago. (Publicado originalmente em 1911). 
Freud, S. (1912). Recomendações aos médicos que exercem a psicanálise. In J. Salomão (Trad.). Obras completas (1996, Vol. 12, pp. 123-133). Rio de Janeiro: Imago. (Publicado originalmente em 1912).

Freud, S. (1918). História de uma neurose infantil. In J. Salomão (Trad.). Obras completas (1996, Vol. 17, pp. 15-129). Rio de Janeiro: Imago. (Publicado originalmente em 1918).

Freud, S. (1937). Construções em análise. In J. Salomão (Trad.). Obras completas (1996, Vol. 23, pp. 275-287). Rio de Janeiro: Imago. (Publicado originalmente em 1937).

Guimarães, L. (2008, maio-outubro). Como formalizar um caso clínico? $A$ Sephallus - Revista eletrônica do grupo Sephora, 3 (6). Recuperado a partir de: http://www.isepol.com/asephallus/numero_06/artigo_04.htm

Jerusalinsky, A. (2008). Considerações acerca da avaliação psicanalítica de crianças de três anos - AP3. In R. Lerner \& M. C. Kupfer (Orgs.), Psicanálise com crianças: clínica e pesquisa. (pp. 117-136). São Paulo: Escuta.

Kupfer, M. C. \& Voltolini, R. (2008). Uso de indicadores clínicos em pesquisas de orientação psicanalítica: um debate conceitual. In R. Lerner \& M. C. Kupfer (Org.), Psicanálise com crianças: clínica e pesquisa. (pp. 93-108). São Paulo: Escuta.

Lacan, J. (1988). Función y campo de la palabra y del lenguaje en psicoanálisis. Escritos. Buenos Aires: Siglo XXI.

Lerner, R. (2008). Apresentação. In R. Lerner \& M. C. Kupfer (Org.), Psicanálise com crianças: clínica e pesquisa. (pp. 5-14). São Paulo: Escuta.

Lévy, R. (2008). O infantil na psicanálise. Rio de Janeiro: Vozes.

Porge, E. (2009). Transmitir a clínica psicanalítica: Freud, Lacan, hoje. Campinas: Editora Unicamp.

Russo, E. (2011). Acerca de la discusión de material clínico. In M. Vorchheimer (Coord.), Anais, 33 Simposio Anual: Relatos de la Clínica, (pp. 272-279). Buenos Aires: APdeBA. 